\title{
Cidade possível, Araés: olhares Para o Bairro Araés - Cuiabá-MT
}

\author{
Ciudad posible, Araés: miradas para el Barrio Araés - Cuiabá-MT \\ City possible: glances for the Araés Neighborhood - Cuiabá-MT
}

\author{
Fabiane Krolow ${ }^{1}$ \\ Paula R. R. Libos ${ }^{2}$ \\ José Serafim Bertoloto ${ }^{3}$ \\ Benedito Dielcio Moreira ${ }^{4}$
}

\begin{abstract}
Resumo
O artigo tem como objetivo propor uma reflexão sobre as práticas/ações de intervenções urbanas, um olhar para as estéticas emergentes na cidade, apresentando a leitura da intervenção "Cidade Possível, Araés", realizada no Bairro Araés, na cidade de Cuiabá-MT, proposta pelo grupo de pesquisadores do Programa de Pós-graduação em Estudos de Cultura Contemporânea da Universidade Federal de Mato Grosso - UFMT. Como evidenciar uma proposta de ocupação, um coletivo de transformações socioculturais, de alternativas para as estéticas emergentes na cidade, são os caminhos percorridos pelo grupo. Nesse texto também, a escolha do local, as discussões para a criação do evento ocorrido no dia 21 de abril de 2018 e uma análise posterior, observando o espaço hoje e mundos possíveis através das ações realizadas na intervenção.
\end{abstract}

Palavras-chave: Cidade Possível. Intervenção Urbana. Estéticas Emergentes. Cuiabá-MT.

\section{Resumen}

El artículo tiene como objetivo una reflexión sobre las praticas/acciones de intervenciones urbanas, una mirada a las esteticas emergentes en la ciudad, mostrando la lectura de la internvención "Ciudad posible, Araes", realizada en el barrio Araes, en la ciudad de Cuiabá, propuesta por el grupo de investigadores del Programa de Posgraduación en Estudios de Cultura Contemporánea de la Universidad UFMT. Como evidenciar una propuesta de ocupación, un colectivo transformaciones socioculturales, de alternativas para las estéticas emergentes en la ciudad. Los caminos recorridos por el grupo, la elección del local y sus discusiones para la creación del evento ocurrido el día 21 de abril de 2018 y un análisis posterior observando el espacio hoy y mundos posibles a través de las acciones realizadas en la intervención.

Palabras clave: Ciudad Posible. Intervención Urbana. Estéticas emergentes. Cuiabá.

\section{Abstract}

This work was developed in order to bring a reflection about the practices / actions of urban interventions, a look at emerging aesthetics in the city, presenting the reading of the intervention "Cidade Possivel, Araés" held in the Araés neighborhood in the city of Cuiabá proposed by the group of researchers from the Graduate Program in Contemporary Culture Studies at UFMT. As evidenced by a proposal of occupation, a collective sociocultural transformations, alternatives to emerging aesthetics in the city. The paths covered by the group, the choice of location and their discussions for the creation of the event occurred on April 21, 2018 and a later analysis observing the space today and possible worlds through the actions taken in the intervention.

\footnotetext{
${ }^{1}$ Mestranda no programa de Pós-Graduação em Estudos de Cultura Contemporânea/UFMT.

2 Doutoranda no programa de Pós-Graduação em Estudos de Cultura Contemporânea/UFMT.

${ }^{3}$ Doutor em Comunicação e Semiótica, PUC/SP; Professor Colaborador do PPGECCO/FCA/UFMT; Docente no Departamento de Arquitetura e Urbanismo e Titular do Programa de Pós-Graduação em Ensino da Universidade de Cuiabá; Cuiabá, Mato Grosso serafim.bertoloto@gmail.com.

${ }^{4}$ Doutor em Educação, Universität Siegen, Alemanha, professor colaborador do Programa de Pós-graduação em Estudos de Cultura Contemporânea-UFMT dielcio.moreira@gmail.com.
} 
Key-words: Possible City. Urban intervention. Emerging aesthetics. Araés. Cuiabá-M.

\section{Introdução}

Outras possibilidades de olhar o outro, o lugar, a cidade e as realidades, vem ao encontro do pensar coletivo, de alternativas para as estéticas emergentes na cidade. $\mathrm{O}$ contemporâneo carrega uma carga de transformações socioculturais avassaladoras, trazendo para a vida cotidiana o individualismo, o avanço tecnológico e um coletivo anônimo que procura de alguma forma referências identitárias de outrora, hoje esquecidas, perdidas no cotidiano.

A relação eu/outro não pode ser compreendida como relação entre um sujeito e um objeto, tampouco como uma relação entre sujeitos, mas como relação acontecimental entre "mundos possíveis". O outro não é nem um objeto nem um sujeito, mas a expressão de mundos possíveis (LAZZARATO, 2006, p. 250).

Estéticas emergentes na cidade e a proposta de criar novos espaços possíveis foi o desafio dado ao grupo de pesquisadores do programa de Pós-Graduação em Estudos de Cultura Contemporânea, um desafio que começou quando fomos provocados a escolher um espaço da cidade possível para uma intervenção urbana. Os pesquisadores envolvidos na proposta discutiram entre distintas situações emergentes na cidade, quais seriam os espaços possíveis.

\section{A caminhada até o "Cidade Possível, Araés"}

Entre os temas discutidos desde o início, tínhamos a questão de estarmos às vésperas do tricentenário da cidade. Foram discutidos, então, entre temas e espaços, questões relacionadas à Cuiabá, capital do Estado de Mato Grosso, como o calor, a arte cuiabana, a cultura cuiabana, e a possibilidade de olhar para o espaço acadêmico, com foco em espaços de arte na universidade, o que ocupou um bom tempo do debate. Todavia, os problemas urbanos vividos por Cuiabá prevaleceram. Então, surgiu a hipótese do bairro Araés, entre as ruas Desembargador José de Mesquita e Rua Osório Duque Estrada, espaço onde já existia uma iniciativa artística.

Devido à presença dos indígenas Araés, situado naquele local, no passado foi batizado de Araés, um bairro de grande relevância histórica, localizado na região central da capital, dividido entre as regiões Leste e Oeste (SANTOS et al., 2009). No bairro residem famílias 
tradicionais, artistas, personalidades da sociedade mato-grossense e negros descendentes de escravos, que por décadas trabalharam nos garimpos. A região para a qual estamos olhando se localiza entre as quatro vias mais movimentadas da cidade, sendo elas a Avenida Mato Grosso, Avenida Historiador Rubens de Mendonça, Avenida Miguel Sutil e a Rua Desembargador José de Mesquita (rua, que liga as Avenidas Miguel Sutil e Mato Grosso dentro do perímetro do bairro Araés).

Tínhamos então a tarefa de visitar o local, com o olhar sensível ao que de fato significa esse espaço na cidade de Cuiabá. Fomos conhecer o espaço do Ateliê Boca de Arte, do artista Gervane de Paula, nome que faz um trocadilho com a existência de uma Boca de fumo localizada em um outro espaço do bairro, onde os pesquisadores intitularam como "ilha", situada abaixo de uma mangueira, ao lado da moto (FOTO 01), espaço que pode ser melhor visto na foto 02 . Temos uma parte do bairro Araés como foco para novos olhares. É um espaço no centro da cidade, delimitado, "área de preservação permanente (APP)", às margens do córrego da Prainha, ainda correndo a céu aberto. É o nosso principal e polêmico concretado córrego, que nomeia a principal avenida do centro histórico da cidade. Estamos em um lugar que, ao mesmo tempo, geograficamente, está no centro da cidade e, culturalmente na vida urbana, "marginalizado".

A leitura do caminhar neste espaço é a de um espaço na cidade onde pode ser o descaso e a falta de manutenção. O córrego está canalizado com efluentes de esgoto no seu leito, o que traz ao bairro a degradação ambiental, comprometendo a saúde, além de influenciar na paisagem urbana. As edificações se mostram em formas características residenciais, no entanto não se vê os moradores. Percebe-se que o córrego e a sua situação atual, com o relevo um pouco acidentado e vegetação sem cuidados, gerou uma barreira nesse espaço público. 
RELACult - Revista Latino-Americana de Estudos em Cultura e Sociedade

Revista Latinoamericana de Estudios en Cultura y Sociedad | Latin American Journal of Studies in Culture and Society V. 05, no 03, set-dez., 2019, artigo no 1406 | claec.org/relacult |e-ISSN: 2525-7870

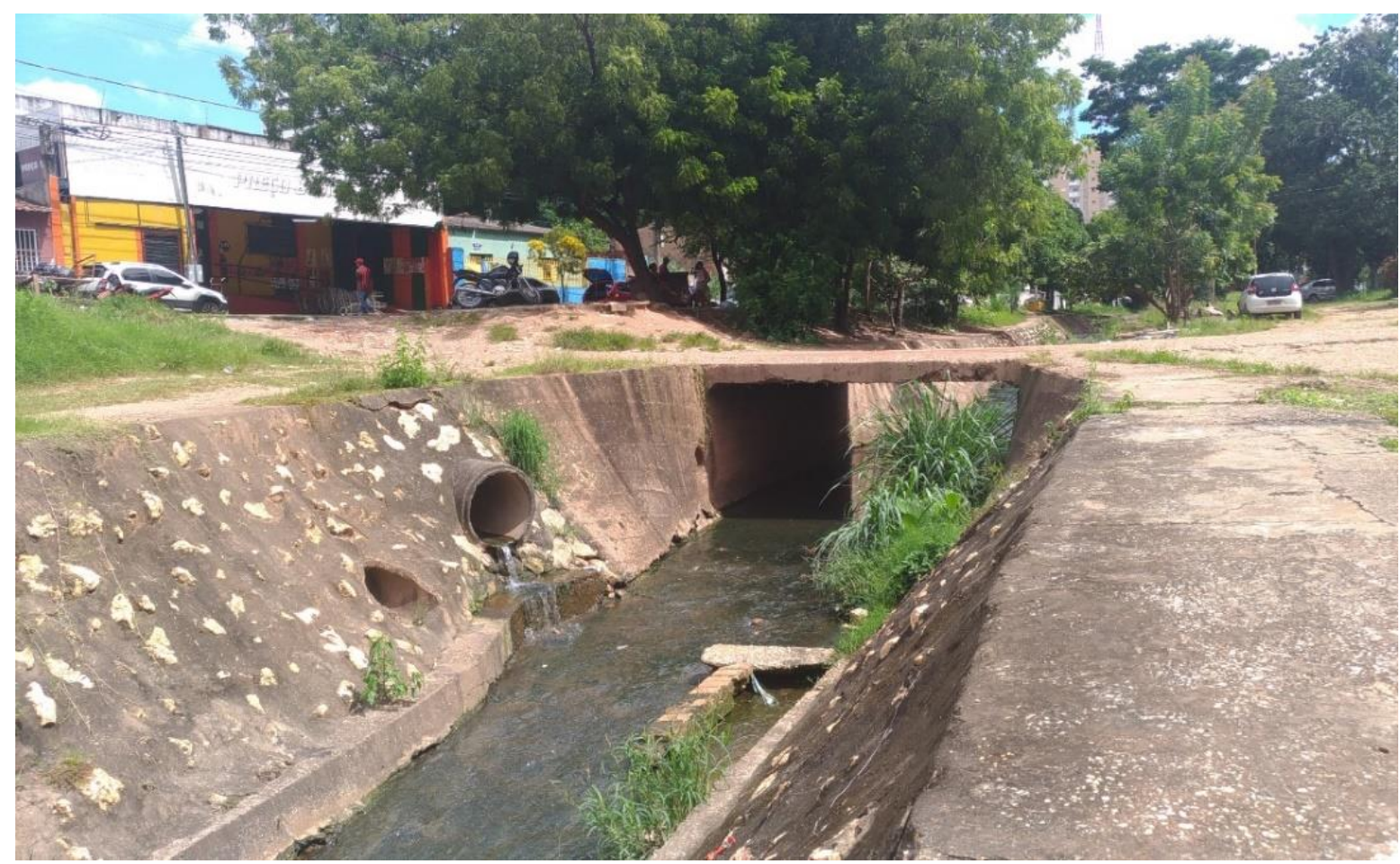

Foto 01 - O córrego, como barreira no espaço público.

Fonte: Fabiane Krolow, 2018

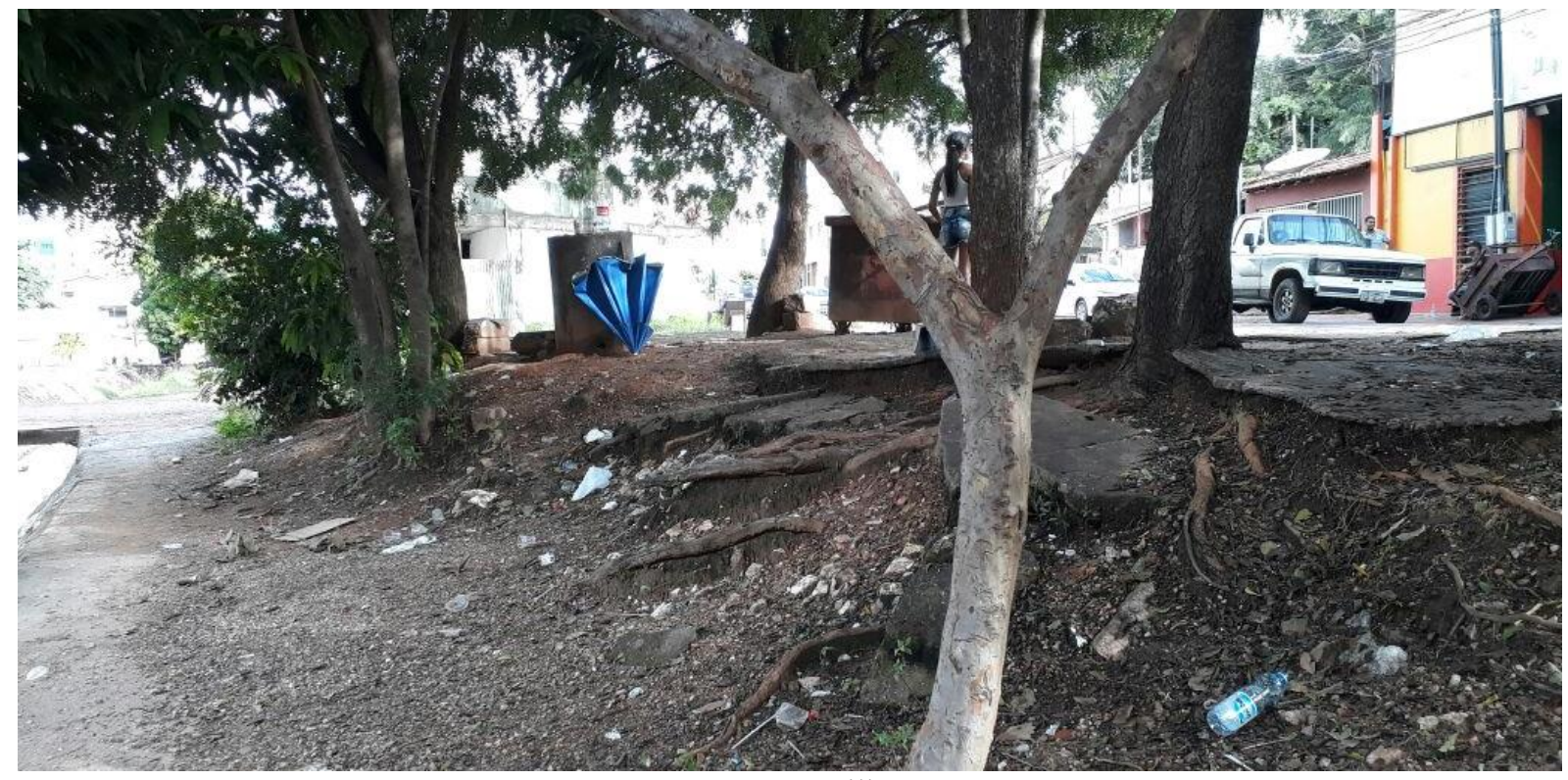

Foto 02 - "A ilha".

Fonte: Paula Roberta Ramos Libos, 2018.

Há um trecho linear às margens do córrego, ausente de vegetação, o que gera uma sensação de "desproteção". Já outro trecho curvilíneo, em uma área mais extensa da margem acolhe, acolhimento esse que pode ser devido à presença de vegetação de grande porte, mais densa, convidativa para uma caminhada e exploração do lugar. É perceptível um potencial "pulmão verde" (FOTO 03), o que reduziria o calor nessa cidade de 40 graus e poderia favorecer o clima urbano como um todo, permitindo assim novos mundos possíveis ao local. 


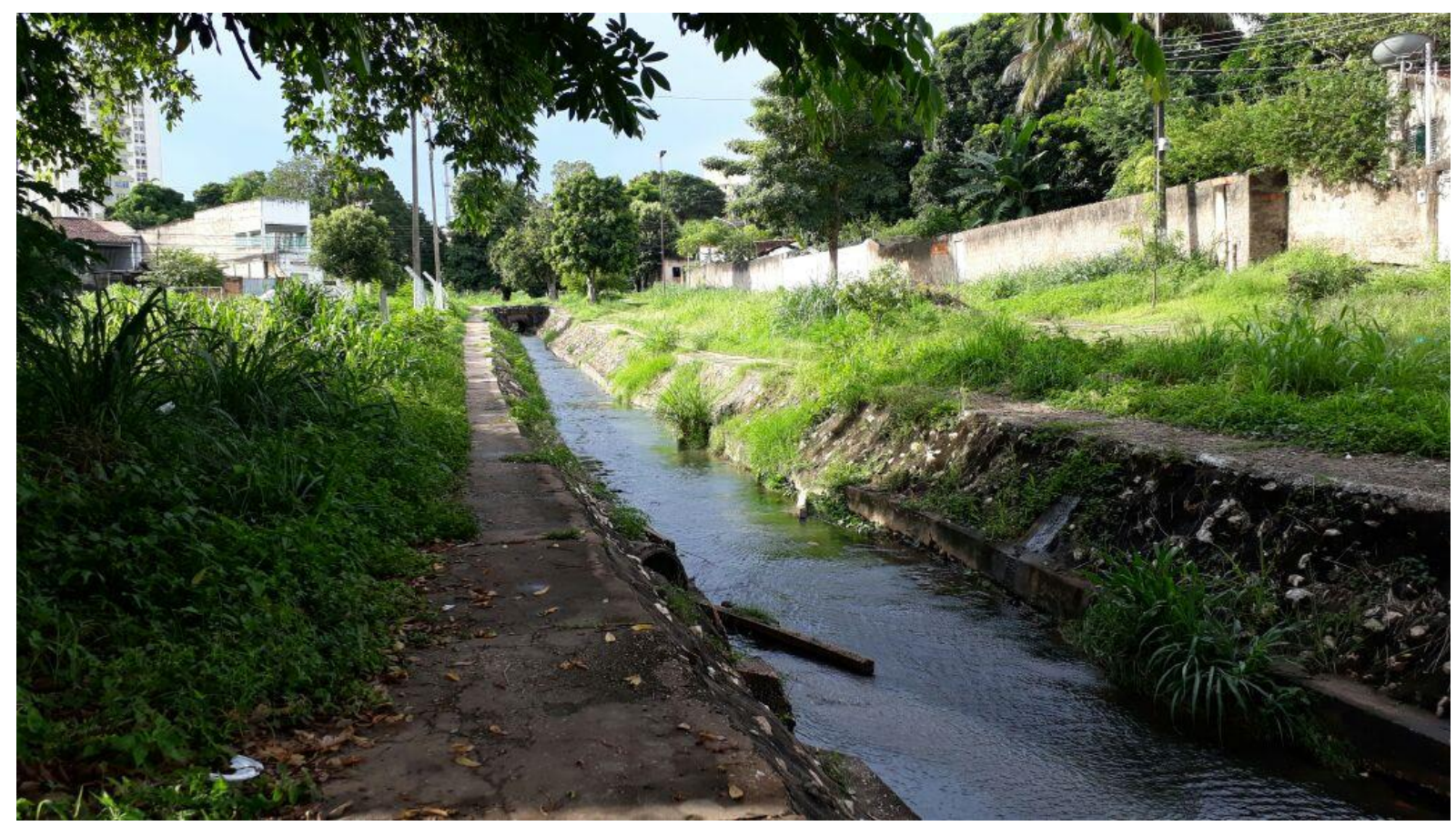

Foto 03 - Potencial "pulmão verde".

Fonte: Paula Roberta Ramos Libos, 2018.

A possibilidade de olhar para as margens do córrego e à sua "desproteção", levou o grupo a pensar em uma proposta para além das intervenções artísticas, ou seja, em buscar apoio para um possível plantio de árvores de grande porte por meio de agenciamentos com entidades que já desenvolvem este tipo de ações de intervenção urbana na cidade. Foi buscado então o contato com o projeto "Ação verde", conduzido pelo Instituto Ação Verde, uma organização da Sociedade Civil de Interesse Público que tem como objetivo buscar o equilíbrio entre o meio-ambiente, o bem-estar social e a atividade produtiva primária do estado de Mato Grosso, atuando com o fomento de mudas de árvores.

O Instituto teve interesse no evento de intervenção urbana do projeto "Cidade Possível Araés" e disponibilizou técnicos para a análise do local, discussão em conjunto com o grupo e de quais seriam as possibilidades para a ação de plantio, decidindo pela doação de 100 mudas de espécies nativas da região, apropriadas para as Margens do córrego.

Durante as visitas ao local, foram realizadas conversas com lideranças, como fala Lazzarato (2006): “A conversa é um dos agenciamentos mais importantes na transmissão e discussão do discurso e das palavras do outro". Entre os relatos, destacamos as memórias da prática de lavar roupas no córrego e as lembranças de quando as crianças brincavam ali, um hábito que desapareceu entre as crianças com a chegada da pavimentação da rua Alyrio Hugne de Mattos, que margeia o córrego. 
O local escolhido para a intervenção urbana é um exemplo de que é falha a tentativa de imposição de uma visão única de mundo, assim como a impossibilidade de um só mundo possível, conforme mostra Lazzarato (2006). Ao contrário, há a necessidade de abertura para novos mundos possíveis.

As teorias do equilíbrio (a economia política e a sociologia), ou as teorias da contradição (hegelianismo e marxismo), assim como as práticas por estas autorizadas, têm um mesmo horizonte comum: a ideia de que só existe um mundo possível. Reprodução e tomada de poder, equilíbrio e contradição, respondem de maneira paradoxal ao mesmo problema: viver juntos em só mundo possível (LAZZARATO, 2006, p. 71).

Nossa sociedade pode ser entendida como uma sociedade de controle, conforme fala Lazzarato (2006), que mantém um controle de cérebros, que modulam os cérebros para agir no cotidiano urbano capitalista, na sociedade do consumo. As comunicações de massa moldam também os corpos, o que se vê nas edificações, no espaço, de forma a não ser possível no espaço público experiências ${ }^{5}$ como as ditas por Bondía (2002). Entre as investigações realizadas, tivemos a conversa com Antonieta Luísa $\mathrm{Costa}^{6}$, ativista com representatividade no bairro, que nos falou sobre a situação dos moradores, de que não existem possibilidades para experiências no bairro.

As propostas de intervenções para o espaço público nas proximidades do Boca de Arte no bairro Araés propõem ações baseadas em necessidades identificadas a partir das visitas realizadas no local e pelas conversas trocadas com os envolvidos no evento, que fazem parte da comunidade local. Ao olharmos à cidade, para o espaço escolhido para a intervenção urbana, também vemos que por não parar em meio a agitação cotidiana, nada acontece. A proposta da intervenção traz uma necessidade de "dar tempo ao espaço" (BONDÍA, 2002, p. 24) pela emergência de que "As cidades que antes eram símbolo de proteção contra perigos naturais se transformam em locais ameaçadores, de riscos constantes. Mas do que é formada a cidade?" (CAPILÉ, 2017, p. 53).

Podemos ainda ir além para buscar compreender o espaço escolhido para a proposta, o qual está em situação de abandono e perigo, e refletir o porquê de abandonarmos espaços que são nossos:

Para enfrentarmos o mal contemporâneo que nos assombra nos munimos de diplomas, cursos e aprimoramentos, nos encerramos em apartamentos fortificados e cada vez menores, evitamos lugares públicos e áreas expostas demais. $\mathrm{O}$ outro

\footnotetext{
${ }^{5}$ Experiências: na abordagem do texto não podem ser possíveis.

${ }^{6}$ Antonieta Luísa Costa, presidente do Instituto de Mulheres Negras (Imune).
} 
passou a ser uma ameaça e nos acostumamos a relação à distância, intermediadas por computadores, telefones, câmeras de segurança, sistemas de vídeo conferência e redes sociais. Tendo o medo como mediador da nossa relação com o mundo, partilhamos necessidades e advertências com mais destreza do que partilhamos humanidades (CAPILÉ, 2017, p. 52).

O "Cidade possível, Araés", assim como o "Cidade Possível” com o "100em1 dia", busca "um movimento contrário à subjetividade capitalista, tem-se buscado outras formas de enxergar, experimentar e estar na cidade, bem como criar outros modos de estar no mundo, sentir e agir para além do eixo capitalista.” (DAVIES; SANTOS; GUSHIKEN, 2017, p. 90).

\section{Cidade possível, Araés", 21 de abril de 2018}

A cidade "é uma das aderências que ligam indivíduos, família e grupos sociais entre si. Uma dessas resistências que não permitem que suas memórias fiquem perdidas no tempo, que lhes dão ancoragem no espaço" (ABREU, 1998, p. 86). Em sua horizontalidade, a cidade de alguma forma promove interação, o espaço local muitas das vezes se recodificam devido os fluxos que recebem alterando sua forma física e social, transformando-se. Foi o que percebemos na intervenção realizada no Bairro Araés. Como já comentado, o Araés é um dos bairros mais antigos da Capital, localizado na área central. E foi justamente ali que muito da história da cidade se construiu.

Não muito diferente de outras capitais, devido a expansão urbana, o centro da cidade se torna a obsolescência na vida urbana, com a necessidade de uma nova intercomunicação com as pessoas, gerando uma poderosa produção subjetiva de experiência, buscando entender e provocar novas experiências. Foi um pouco disso que aconteceu no dia 21 de abril de 2018: um grupo heterogêneo e multidisciplinar em um episódio subjetivo e processual, marcado por uma experiência urbana ímpar na intervenção urbana naquele espaço.

No dia 21 de abril de 2018, um grupo de pesquisadores, mestrandos e doutorandos, depois de uma caminhada para conhecer o lugar onde seria realizada a intervenção pelos alunos da disciplina de Poéticas Contemporâneas se sentiu desafiado a realizar o evento. Coordenado pela Professora Maria Thereza, o projeto Cidade Possível Araés tinha um objetivo único: despertar olhares, velhos ou novos, e que, em alguns momentos, o espaço do bairro exigia, e parece que de alguma forma isso aconteceu.

\footnotetext{
${ }^{7}$ 100em1 dia: evento realizado com diferentes atrações em um único dia, com o propósito de despertar a atenção para a cidade.
} 
Roda de conversa, artesanato, música, fotografia, teatro, performance entre outras intervenções dentro de um espaço aberto partilhado por imigrantes, moradores, curiosos ou simpatizantes da manifestação cultural ali exposta com a intenção de "atrair" olhares para um espaço de significados da cidade que estão mudos no contexto sócio cultural e urbano. Agora se vê "La ciudad, como el abstracto o real, se presta a ello. Une produce, se percibe y se expresa de multiples formas... Es un este medio de expresiones donde la aportación de los investigadores puede crear debates y encuentros" (BORSANI, 2013, p. 8).

Uma movimentação atípica no bairro, pessoas do local, pessoas diferentes, artistas, alunos, um vai e vem. Curiosos, atuantes, moradores e colaboradores, "Boca de Arte" se torna o centro, o ponto, o local incomum, disposto a contribuir e a receber contribuição desde um olhar, uma palavra, uma ação. E quantos olhares, atentos e dispostos, se cruzando, se afetando permitindo-se afetar e ser afetado. O espaço passa a ser o protagonista do dia, as pessoas coadjuvantes na busca de contribuir com a intervenção; as pessoas estão abertas ao desconhecido, em experiências singulares (BONDÍA, 2002, p. 28).

Esse novo olhar para o espaço, com diferentes mundos possíveis em diferentes experiências possíveis, pode ser visto como na análise "Del espacio al lugar habitado: al concepto de topofilia” de Yori (2007), como espaço vivido.

\begin{abstract}
Como se ve, para Bachelard la topofilia es una categoria poética del espírito desde la cual la percepcion del espacio se mediatiza, no solo por la experiencia sensible que pueda tenerse en el (su posividad), sino fuerte carga imaginativa a traves de cual se podría afirmar que este "entra en valor"; o lo que mismo, en "apropriada significación"; condición que le permite diferenciarse del espacio mesurable de la física o de la geometria para ostentar la categoria de "espacio vivido", o espacio vivenciado (YORY, 2007, p. 49).
\end{abstract}

\title{
3. Ações da intervenção
}

De longe ouve-se a banda Marcial Ranulpho ${ }^{8}$, com sua música convidando a vizinhança a participar desse momento ímpar, uma música com ressonância avassaladora, que invade e atravessa a alma, despertando olhares, ora curiosos, ora atentos e invasivos, permeados pelo amor a música ou pela simples atenção; está dividida com a performance do teatro que invade, constrange e engasga; uma história reproduzida do presente que se funde com o passado; histórias de um povo negro que, instalado naquele bairro, trazem um pouco da

\footnotetext{
${ }^{8}$ A Banda Marcial Ranulpho Paes de Barros surgiu no ano de 2011, criada pelo professor e regente Francisval Costa.
} 
luta pela "consciência negra"; vem à tona aspectos culturais das comunidades de afrodescendentes que desde a década de 70 debatem essa temática.

Outra experiência urbana vivida e partilhada ali naquele local foi o plantio de vegetações de grande porte, às margens do Córrego da Prainha, hoje conhecido como o Córrego do General, um pequeno trecho canalizado, mas não coberto. Diferente da maior extensão do córrego, está à mercê de cuidados, manutenção e atenção, em uma extensão de aproximadamente 300m. Em 1722 esse córrego foi muito importante para a população de Cuiabá, não apenas pelo marco histórico de surgimento e crescimento da cidade, mas porque abastecia seus habitantes fornecendo água, utilizada no dia a dia doméstico, e também como lazer, pois foi outrora piscoso e navegável, explorado devido ao descobrimento de ouro.

O local acima mencionado faz uma segregação de espaço. Ligado por uma pequena travessia, percebe-se um trecho parcialmente cuidado, acolhedor, com uma experiência de "fundo de quintal", possui vegetação densa consolidada de grande porte e outras pequenas ilhas com plantas frutíferas, condimentos e plantas medicinais, um trecho que mesmo acidentado permite a caminhabilidade e traz uma pequena identidade dos moradores ali próximos. Em um segundo trecho observa-se um campo visual amplo e linear, pouco convidativo, pois remete para um efeito de desproteção. $\mathrm{O}$ que a experiência no local nos permite analisar é que podemos ir além de nossa vizinhança e experimentar os encontros possíveis, transformando espaços; que esse local possa ser ressignificado e ocupar na memória das pessoas toda a sua importância e sua história, criando a partir da memória histórica, a memória coletiva (ABREU, 1998)

Cerca de aproximadamente 100 (cem) pessoas participaram no dia do evento de intervenção, ora na música, ora no teatro. Antes, no plantio, estavam acompanhadas da angústia das transformações do local, descritas naquele momento. A importância da ação se deu no modo de percepção e de experiência pessoal com o local, com a cidade. Olhares atentos e distribuídos depositavam naquele movimento ímpar a angústia, na melhoria de uma nova possibilidade. Cidade Possível Araés, sim. É possível o cruzamento de olhares de intervenções com encontros cotidianos, buscando enfrentar alguns problemas urbanos, atribuindo outro ritmo ao lugar. Conforme Lazzarato (2006), "estar em cooperação dever ser um sentir junto, um "se afetar" junto". É certo que as experiências são subjetivas, mas o que tudo indica é que de alguma forma a afecção ocorre. A Foto 04 mostra a ação do plantio das mudas de árvores no entorno do córrego, as ações dos envolvidos diretos no dia do evento. 


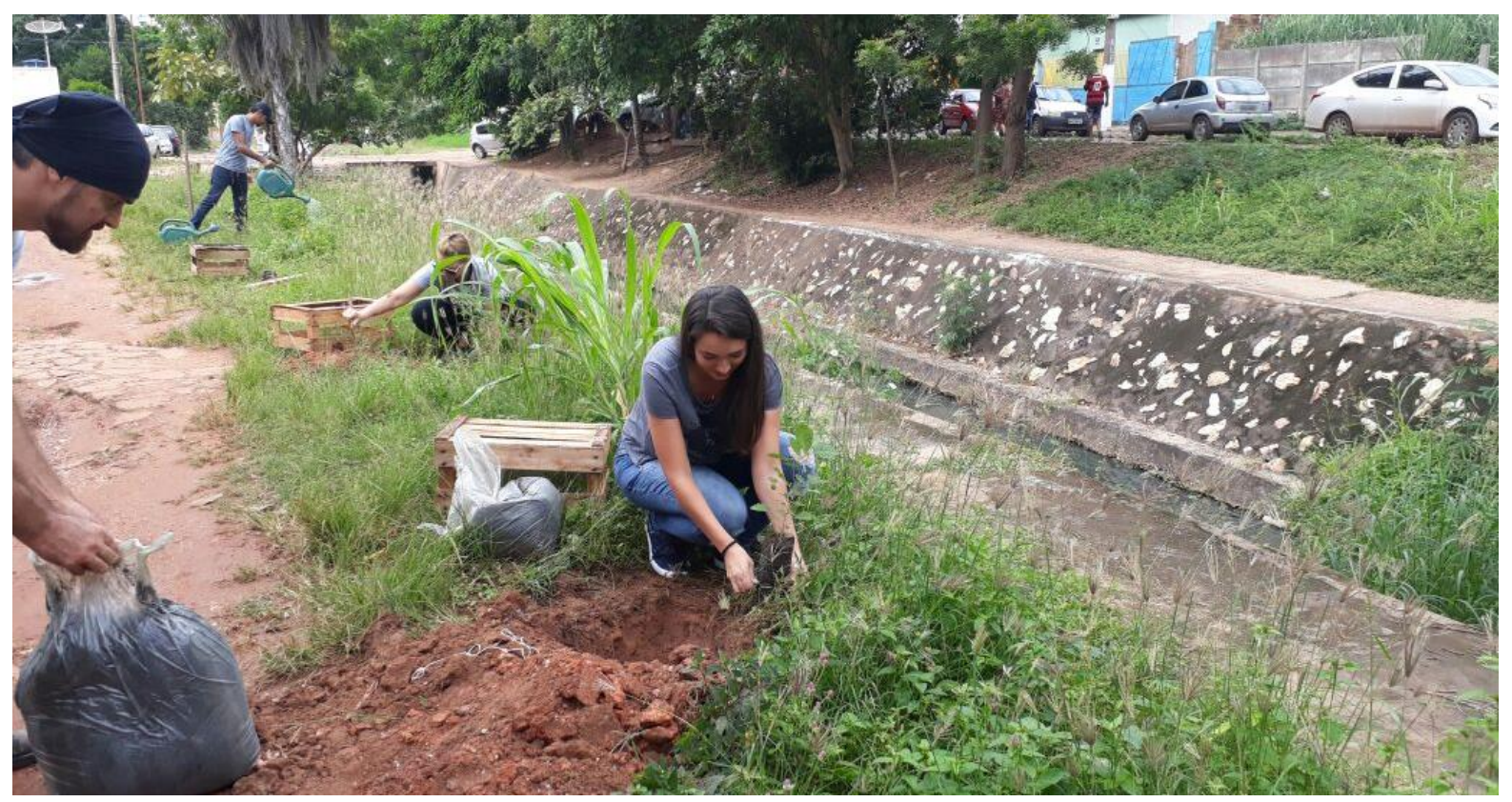

Foto 04 - Plantio de mudas de árvores.

Fonte: Paula Roberta Ramos Libos, 2018.

Vemos na ação de plantio as experiências vividas durante a intervenção:

A subjetividade que se expressa na cooperação entre cérebros se relaciona com a atividade, não segundo categorias da práxis ou do trabalho, mas de acordo com a lógica da criação e realização de possíveis. (LAZZARATO, 2006, p. 134).

Podemos perceber esses possíveis através das experiências propostas na ação:

A experiência é o que nos passa, o que nos acontece, o que nos toca. Não o que se passa, não o que acontece, ou o que toca. A cada dia se passam muitas coisas, porém, ao mesmo tempo, quase nada nos acontece. Dir-se-ia que tudo o que se passa está organizado para que nada nos aconteça (BONDÍA, 2002, p. 21).

Já a ação do plantio pode ser assim vista como experiências que nos tocam, como afirmado por Bondía, e ainda: "ao contrário do trabalho, a criação, a invenção, torna-se também imediatamente pública, uma vez que está aberta a todos; ela se dá diante dos olhos, dos afetos, das inteligências e das vontades de todos." (LAZZARATO, 2006, p. 132), o que é afirmado também por Yory (2007): "lo propio del espacio habitado consiste, justamente, en hacer evidente la específica manera en que, como humanos, nos relacionamos con el mundo a través de la apropiación física y simbólica que de él hacemos". 


\section{Não conclusão e sim processos de novas ações}

É como no dizer da Lazzarato (2006): "Um acontecimento não é a solução de problemas, mas a abertura de possíveis". Passados exatos 30 (trinta) dias da intervenção e eis que retornamos ao local e o cenário que encontramos foi bem diferente do "primeiro encontro": limpo, com uma aparência de habitado (Foto 05). Como na teoria da topofilia de Yory (2007), a possibilidade de ser afetado parece que deu certo, de certa forma já mudou um pouco, um pouco mais atraente. Podemos até nos deixar afetar por um mundo que não existia para nós; passamos a ser atraídos por ele devido à nossa experiência com o local, o nosso ato de habitar com o lugar.

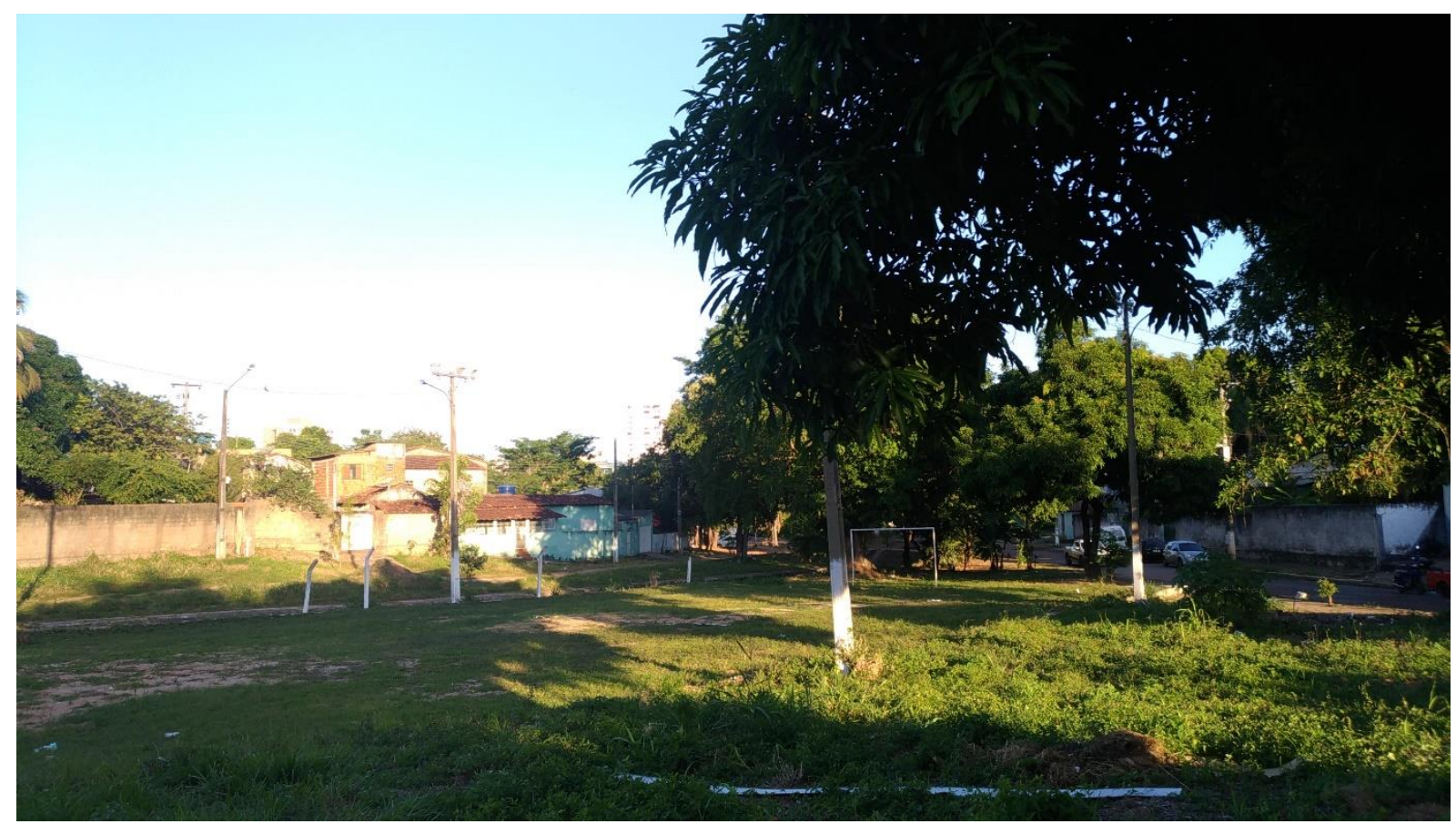

Foto 05 - O espaço limpo, 30 dias após a intervenção.

Fonte: Fabiane Krolow, 2018.

Caiafa (2003, p.96) discute um texto de Deleuze de 1974 em que ele diz que o outrem, aquilo que está ao nosso redor, "introduz o signo do não-percebido no que eu percebo". O que vem de encontro com a experiência pessoal vivida por nós dentro de um espaço nãopercebido, em que de alguma forma aconteceu uma comunicação, pois passamos a percebê-lo, a olhá-lo como um sentimento de espaço possível. Nós nos deslocamos e agimos no espaço da cidade e passamos a produzir uma nova história pessoal com os espaços da cidade, construindo uma memória coletiva, conforme apresentada por Abreu (1998). 
Conversando com os pesquisadores envolvidos nas ações de intervenção no bairro Araés e na ação do plantio de mudas de árvores ouvimos sobre a necessidade de ações como essa: "Efetuar os possíveis que o acontecimento faz emergir é portanto abrir um outro processo imprevisível, arriscado, não antecipado: é operar uma "reconversão subjetiva em nível coletivo" (LAZZARATO, 2006, p. 13),

É através dessa experimentação, que a arte é o meio de trazer ao cidadão a capacidade de se apropriar dos espaços urbanos, cada vez mais abandonados, desordenados e inabitáveis. A vivência de que esses espaços/ambientes podem ser ocupados com afetos, significação, prazer e contemplação, quase sempre levanta essa questão ao sujeito de pertencimento e de modos de vida (AZEVEDO, 2017, p. 16).

Temos então a oportunidade de um novo olhar, uma outra forma de habitar no mundo.

\begin{abstract}
Abrir-se ao possível é acolher, tal como acontece quando nos apaixonamos por alguém, a emergência de uma descontinuidade na nossa experiência; e construir, a partir da nova sensibilidade que o encontro com o outro proporciona, uma nova relação, um novo agenciamento. (LAZZARATO, 2006, p. 18).
\end{abstract}

A cidade é do homem que vive nela, logo, o Araés também é nosso e a intervenção trouxe um novo olhar, um novo significado e certamente uma compreensão nossa em relação aos grupos invisíveis que habitam aquele espaço.

\title{
REFERÊNCIAS
}

ABREU, Mauricio de Almeida. Sobre a memória das cidades. Revista da Faculdade de Letras: Geografia I, Porto, v. XV, p.77-97, 1998.

AZEVEDO, Maria Thereza. Cidade Possível, ou, como podemos criar outros modos de estar no mundo. In: AZEVEDO, Maria Thereza (Org.). Cidade Possível 100em1dia Cuiabá: Pensar, experimentar e reencantar a cidade. Curitiba: Pr: Crv, 2017. Cap. 1. p. 11-22.

BONDÍA, Jorge Larrosa. Notas sobre a experiência e o saber de experiência*. Revista Brasileira de Educação, Campinas, v. 19, n. 2, p.20-28, 2002. Trimestral.

BORSANI, María Eugenia. Logos y metrópolis: sobre fronteras, saberes y ciudades. In: BRAGA, Joaquim et al (Org.). Between categories, beyond boundaries: Arte, ciudad e identidad. Granada: Libargo, 2013. p. 13-27.

CAIAFA, Janice. Comunicação e diferença nas cidades. Lugar Comum: Estudos de mídia, cultura e democracia, Rio de Janeiro, v. 18, p.91-102, 2002. 
CAPILÉ, Juliana. A crise ecológica humana e a resposta do Cidade Possível 100em1diaCuiabá. In: AZEVEDO, Maria Thereza (Org.). Cidade Possível 100em1dia Cuiabá: Pensar, experimentar e reencantar a cidade. Curitiba: Pr: Crv, 2017. Cap. 5. p. 51-59.

DAVIES, Silvia Mara; SANTOS, Vera Lúcia Xavier dos; GUSHIKEN, Yuji. Onças de João Sebastião e "crionças" de Cuiabá: Artes visuais e intervenção urbana para uma Cidade Possível. In: AZEVEDO, Maria Thereza (Org.). Cidade Possível 100em1dia Cuiabá: Pensar, experimentar e reencantar a cidade. Curitiba: Pr: Crv, 2017. Cap. 8. p. 89101.

LAZZARATO, Maurizio. As revoluções do capitalismo. Rio de Janeiro: Record, 2006.

PIMENTEL, Romilda S. da Silva, BORDEST, Suise Monteiro. A percepção ambiental das pessoas que ocupam as áreas próximas à foz do Córrego Prainha. Disponível em: http://www.ufmt.br/revista/arquivo/rev10/percepcao_ambiental.html. Acessado em 27 de maio de 2018.

SANTOS, Adriana Bussiki et al (Org.). Perfil Sócio Econômico de Cuiabá. 4. ed. Cuiabá: Ipdu, 2009. $530 \mathrm{p}$.

YORY, Carlos Mario. DEL ESPACIO OCUPADO AL LUGAR HABITADO: Una aproximación al concepto de topofilia. Barrio Taller: La ciudad pensada, Bogotá, v. 12, p.47-63, 2007. Anual. 